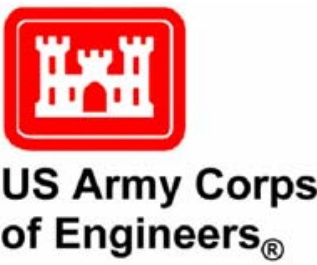

\title{
Jetty Spur Functional Design at Coastal Inlets; Effects on Nearshore Circulation and Potential Sediment Movement
}

by William C. Seabergh

PURPOSE: This Coastal and Hydraulics Engineering Technical Note (CHETN) discusses the effects of connected and detached spurs on sediment transport and circulation in the vicinity of a coastal inlet jetty. The influence of spur orientation on the magnitude and pathways of these processes is detailed based on observations in the field and comprehensive laboratory measurements. A companion technical note, CHETN-IV-61 (Seabergh and Krock 2003), discusses existing jetty spurs in the United States and presents initial Coastal Inlet Research Program (CIRP) physical model jetty spur results.

BACKGROUND: A jetty spur is a relatively short structure extending at an angle from the main jetty axis that protects a navigation channel. The spur diverts sediment that may shoal in the channel back towards the beach, where it can nourish the beach. Spurs are usually constructed of rock rubble similar to the connecting jetty. If longshore sediment transport is primarily unidirectional, sediment will deposit on the upcoast side of the inlet, and the downdrift beach will erode. For this case, spur jetties can provide a protected area within which land- or water-based equipment can dredge and bypass the accumulated sediment.

Spurs are typically nearly perpendicular to the jetty, but may also be constructed at some angle with respect to the jetty up to about $45 \mathrm{deg}$. These types of spurs have the potential to reduce maintenance dredging volumes and to divert sediment back to the beach. At Siuslaw River Inlet, OR (Figure 1), spurs reduced channel maintenance by 133,800 cu m per year (Bottin 1997).

The spur acts as a deflector for the nearshore current that is generated by waves breaking at an angle to the main axis of the jetty, by the alongshore component of the wind, and by the tidal current. This current may entrain sand from the beach. The spur's basic function is to alter the path of the sediment-laden current, redirecting it shoreward and updrift. Ideally, sediment will be deposited on the beaches adjacent to the jetty. Typically, longshore and tidal currents are turned seaward as they approach a coastal inlet jetty. Flow is usually seaward along the outer side of a jetty and, in the absence of a spur, it is typically drawn into the navigation channel during flood flow. The region on the sea side of the updrift jetty may have a fillet as sand accumulates against the jetty. This sediment may be entrained and carried around the jetty tip and eventually encroach on the navigation channel. During ebb tide, the longshore flow diverted seaward by the jetty may be parallel to the ebbing channel current, and sediment from the shore side of the jetty can be entrained into the ebb current and delivered to the ebb shoal, where it potentially can bypass naturally to the downdrift beach. However, this sediment may be transported back into the navigation channel by the flood current and result in shoaling or continued transport to the ebb shoal or flood shoal. 


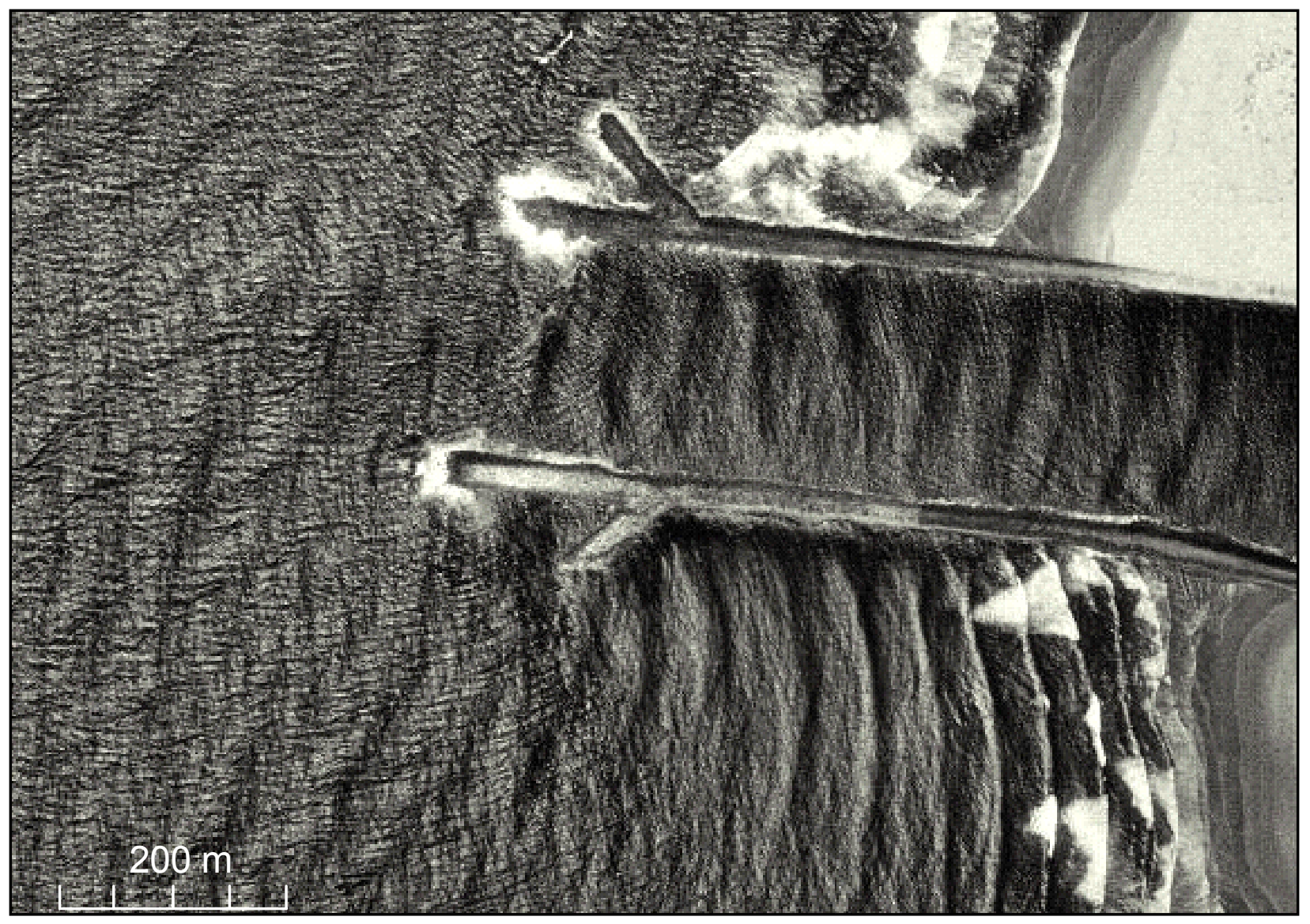

Figure 1. Example of jetty spurs at Siuslaw River Inlet, OR. Spur lengths are $122 \mathrm{~m}$

Spurs may also act as a breakwater and provide wave height reduction along the local beach and the structure itself. If added to a weir-jetty system (for information about weir jetties, see Seabergh 2002), a spur may provide wave reduction for dredging operations in the deposition basin and minimize sediment transport seaward of the weir (Seabergh 1983).

Bypassing of sediment around the spur would most likely occur during storms, when a wide surf zone might permit sediment transport seaward of the spur. Another possible benefit for a new jetty system with spurs is that the outer tips of the jetties may not need to extend seaward as far as a system without a weir jetty, as seaward transport along the jetty that would move into the channel is minimized (Bottin 1981).

The spur jetty may also be included as part of a beach nourishment plan to aid in maintaining and protecting the sediment in the beach area (Walther and Dombrowski 1999). Beach-fill projects tend to saturate the nearshore with sand and, until equilibrium is reached, excess sediments may move toward the navigation channel. A spur may keep the excess material in the beach zone. The spur could be used on a downdrift jetty, as well as a more typical updrift jetty, if it was thought that the nourished downdrift beach might have a tendency to locally feed back along the downcoast jetty towards the navigation channel. Return of sediment towards the channel could be due to refraction of waves over the ebb shoal. Also, the downdrift spur would function during wave-direction reversals. 
Kraus and Heilman (1997) considered spur jetties for Packery Channel, TX, to provide beach protection near the jetties. They tested functioning of the spur design with the shoreline response model GENESIS (Hanson 1987; Hanson and Kraus 1989; Gravens et al. 1991). The spurs were eliminated from the design because of concern about the expense of bypassing sediment that would accumulate behind the spurs; the conclusion was that dredging the channel would be less costly for that particular situation.

Previous work concerning spur design is somewhat limited. Sasaki and Sakuramoto (1984) discussed prototype experiments for "rip current barriers," or spurs, at two small-craft harbors in Japan. They recommended that length of the spurs be greater than the surf zone width and that they be located outside the surf zone.

PHYSICAL MODEL EXPERIMENTS OF SPURS: A pilot study of spurs was initiated in the CIRP physical inlet model. The physical model facility (Seabergh 1999) is a large research basin (46-m-wide by 99-m-long) with an idealized inlet and smooth offshore contours (Figure 2).

Short-period waves and tidal currents can be simulated in this facility. A scale of 1:50 is applied to this generic inlet configuration. Twin parallel jetties were placed at the inlet entrance, and various spur configurations were examined. Wave height, wave period, and channel current were varied to produce different surf and longshore-current conditions. Wave height was measured with capacitance-type gauges, and observations of current patterns and sediment pathways were made on the beach side of the jetty with dye and a lightweight sediment tracer, respectively.

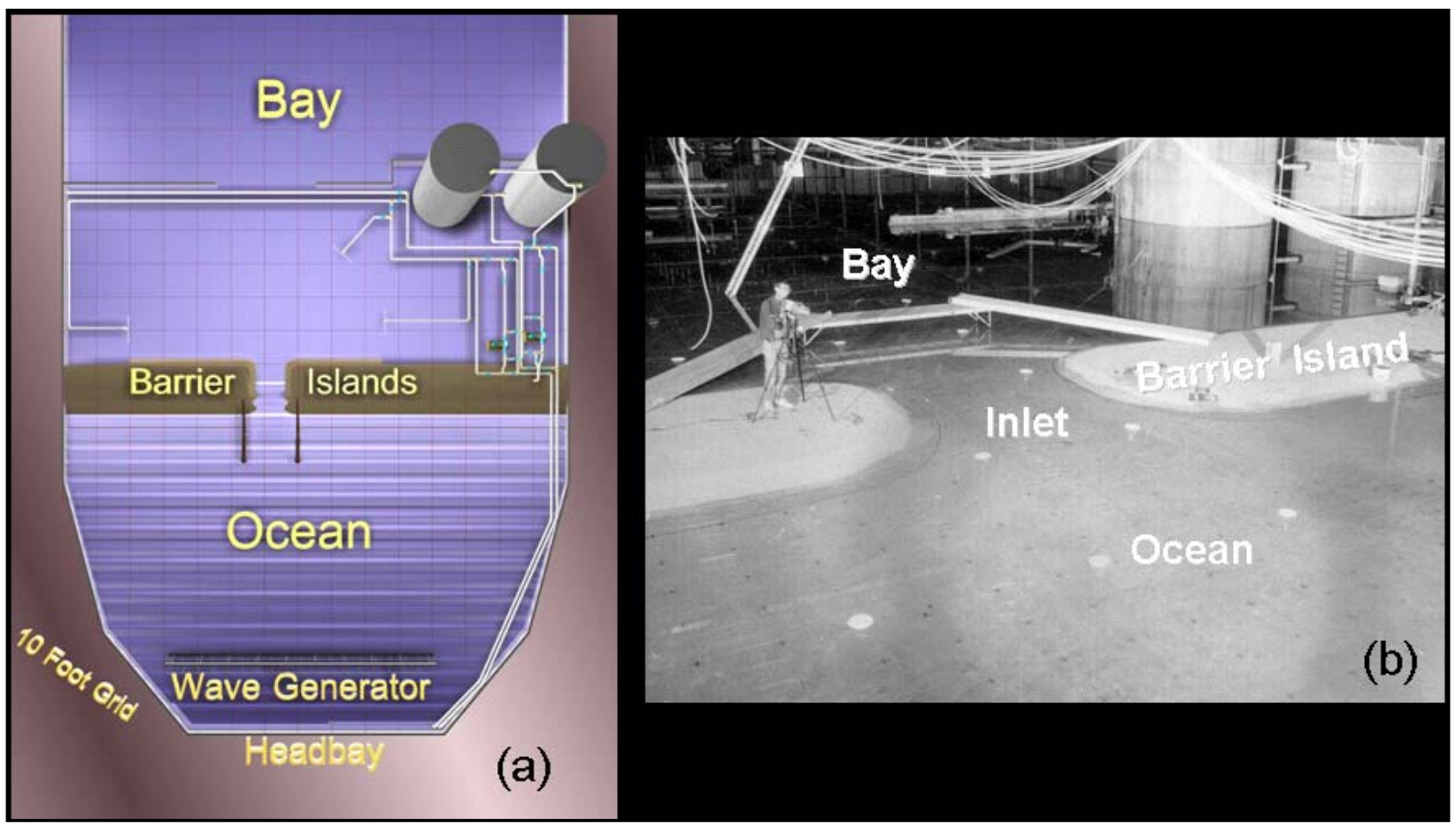

Figure 2. CIRP idealized inlet (a) physical model layout and (b) photograph of idealized inlet model 
WATER CIRCULATION ALONG BEACH SIDE OF JETTY: A parallel jettied inlet system was modeled in the idealized inlet facility to examine flow patterns and sediment tracer movement that occur on the beach side of a jettied inlet. Figure 3 shows a photograph in the laboratory of wave-generated longshore current (emphasized with dye) deflecting offshore along a jetty.

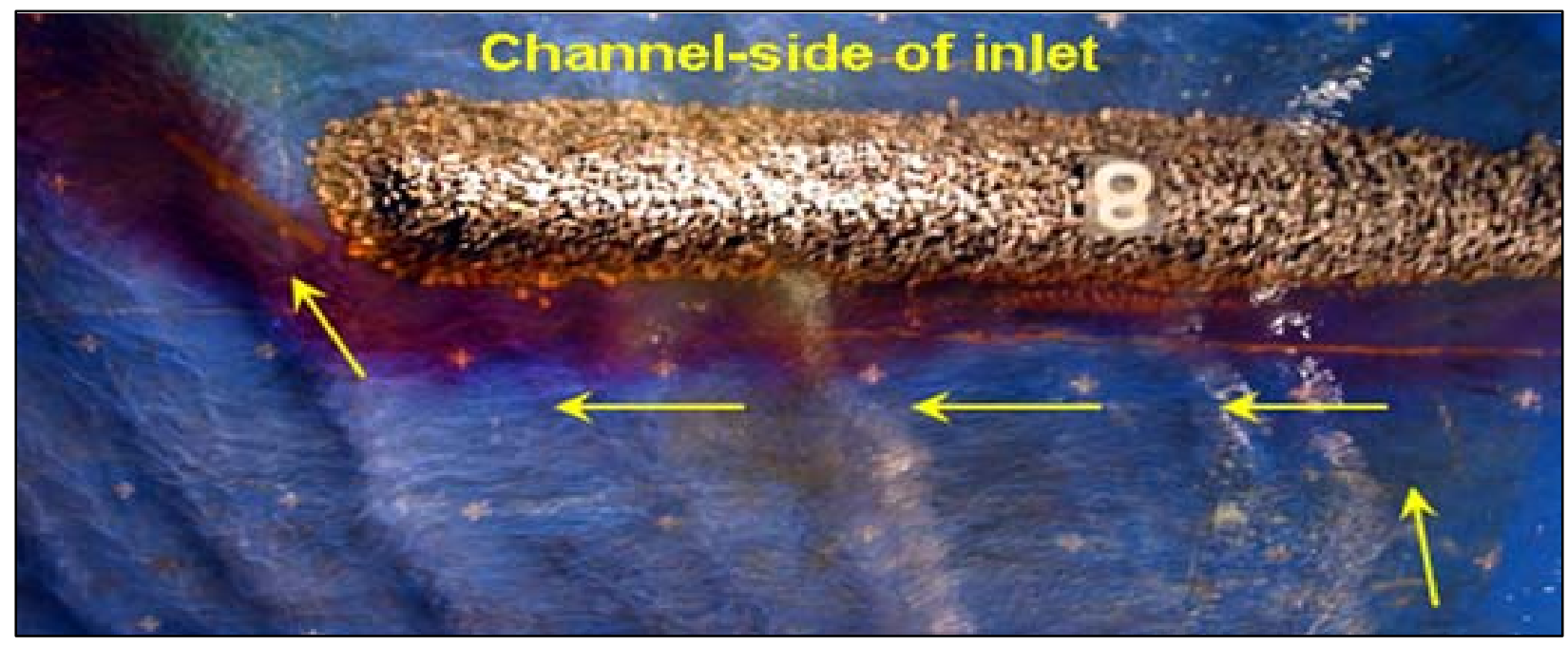

Figure 3. Arrows show direction of water movement due to alongshore current being deflected offshore by a jetty

Figure 4 shows plots of current magnitude and current direction measured at two different jetty types. One side of the inlet is shown, with waves in relatively deep water approaching initially at a 20-deg angle with the shoreline. The left-hand current vector plot is for a jetty that is porous with respect to wave reflection, typical of rubble-mound breakwaters, and the right-hand current vector plot is for a jetty with a highly reflective surface, typical of vertical sheet pile. In each case, the longshore current is deflected seaward. For the porous breakwater, the current approaches the jetty and is then deflected seaward along the jetty. For the highly reflective jetty, the reflected waves promote a clockwise circulation cell along the jetty, shifting the rip current from the beach about $100 \mathrm{~m}$ upcoast. For either jetty type, the longshore current flows toward the tip of the jetty, potentially contributing to local beach erosion. The laboratory experiments discussed in this CHETN included only rubble-mound breakwaters.

SEDIMENT CIRCULATION ALONG JETTY: The current previously described would be expected to entrain sediment when combined with the oscillatory current of the incident waves and transport it toward the channel. With the addition of a flood current, there would be additional sediment transport and curvature of the current vectors toward the inlet around the jetty tip. Figure 5 shows the result of an experiment with waves and a flood current using a coal sediment tracer in the physical model. The sediment tracer moved from the upcoast beach face, where it was introduced into the physical model in the surf zone, toward the jetty. The tracer then turned seaward and moved from the base of the jetty towards the jetty tip. The flood current transported the tracer around the jetty tip and into the navigation channel. 


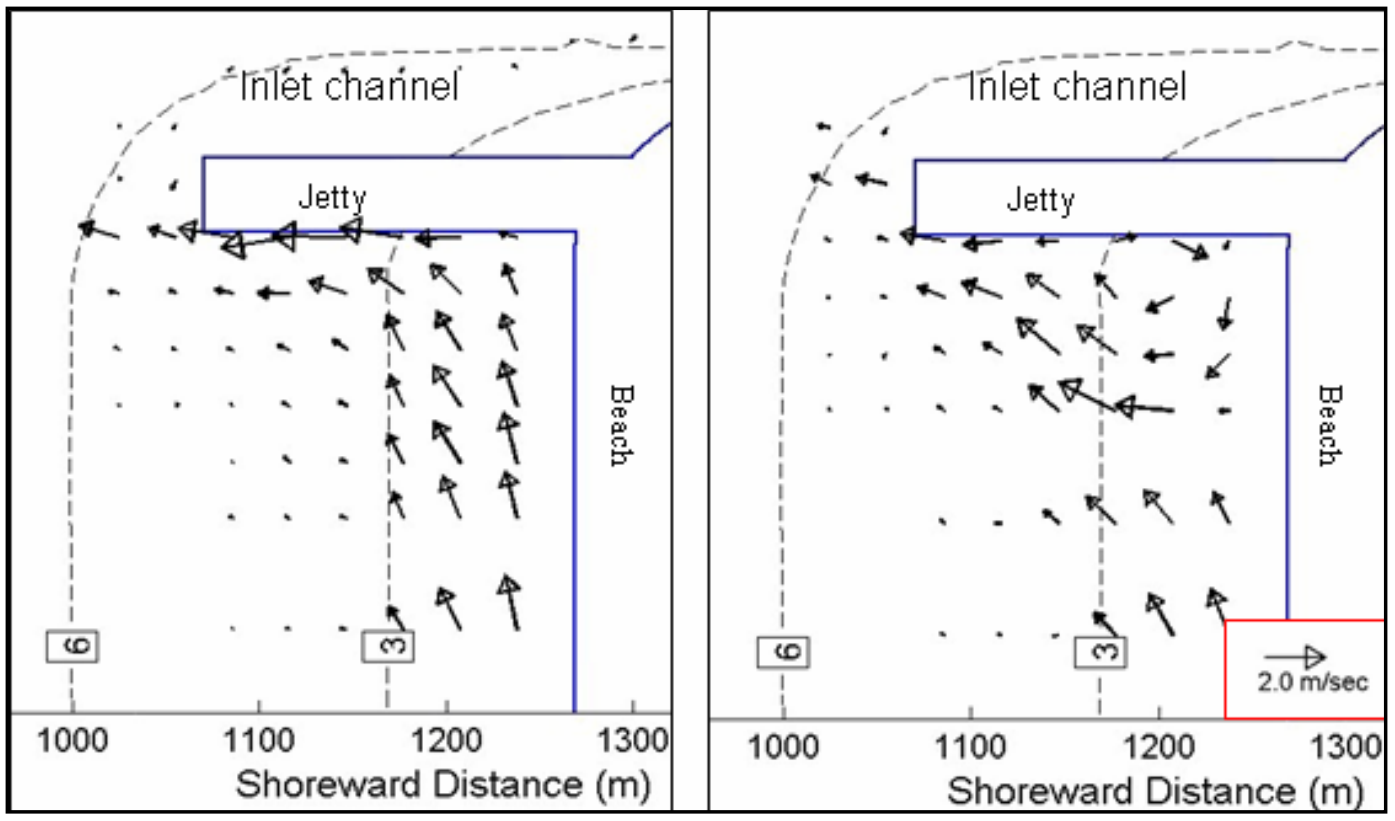

Figure 4. Current vectors produced by wave-generated current approaching a porous, wave-absorbing jetty (left side) and a highly reflective jetty (right side). The incident wave angle is $20 \mathrm{deg}$, in relatively deep water with a 2-m wave height and an 11-sec wave period (Data from Seabergh et al. 2005)

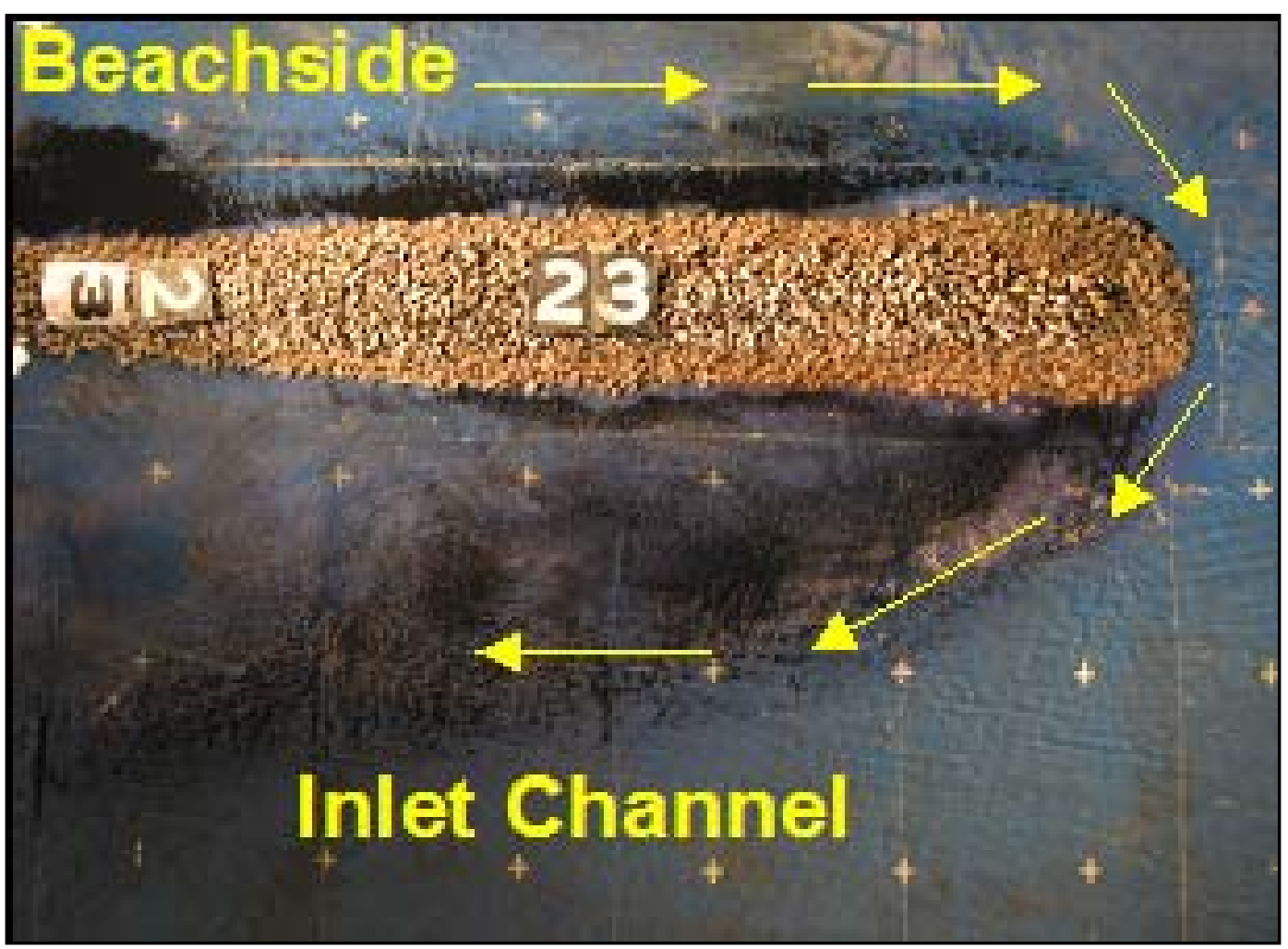

Figure 5. Coal sediment tracer transported around jetty tip by wave-generated and flood tidal currents 
It should be noted that a flood current need not be present for the sediment to be introduced into the channel. Conditions with only waves will wrap the sediment around the jetty tip, as wave crests are diffracted into the lee of the jetty. The wave wrapping is somewhat dependent on the depth at the jetty tip and the magnitude and direction of the waves.

This section and the previous one illustrate currents that may move sediment from the beach adjacent to a jetty and the resultant sediment movement that may induce navigation channel shoaling. The tendency for sediment movement into the navigation channel follows the popular notion that a coastal inlet is a sink, or depository for coastal sediments. The remainder of this CHETN will investigate and discuss some add-on-type structures that may help to reduce navigation channel shoaling.

LABORATORY STUDY OF CHANNEL SHOALING REDUCTION STRUCTURES: A definition sketch is provided in Figure 6 for the parameters to be discussed. The directional convention for spur orientation and current direction is 0 -deg, directed offshore along the shoreperpendicular jetty, with angle increasing in a counter-clockwise direction (see Figure 6). Sixteen structures were examined in the laboratory (Figures 7 and 8). Not all were jetty-attached structures, but are included here as possible useful candidates due to their small footprints. Configurations 1-3 were discussed in CHETN-IV-61 and are included here for completeness. Configurations 4-12 are various spurs and Configurations 13-16 are detached structures. Configurations 13-15 were added to the study to examine if a small offshore breakwater would have a diversionary effect on the longshore current. Configuration 16 is based on an orientation as studied by Miroshnichenko et al. (1985). Table 1 provides information on the structures and experiment results.

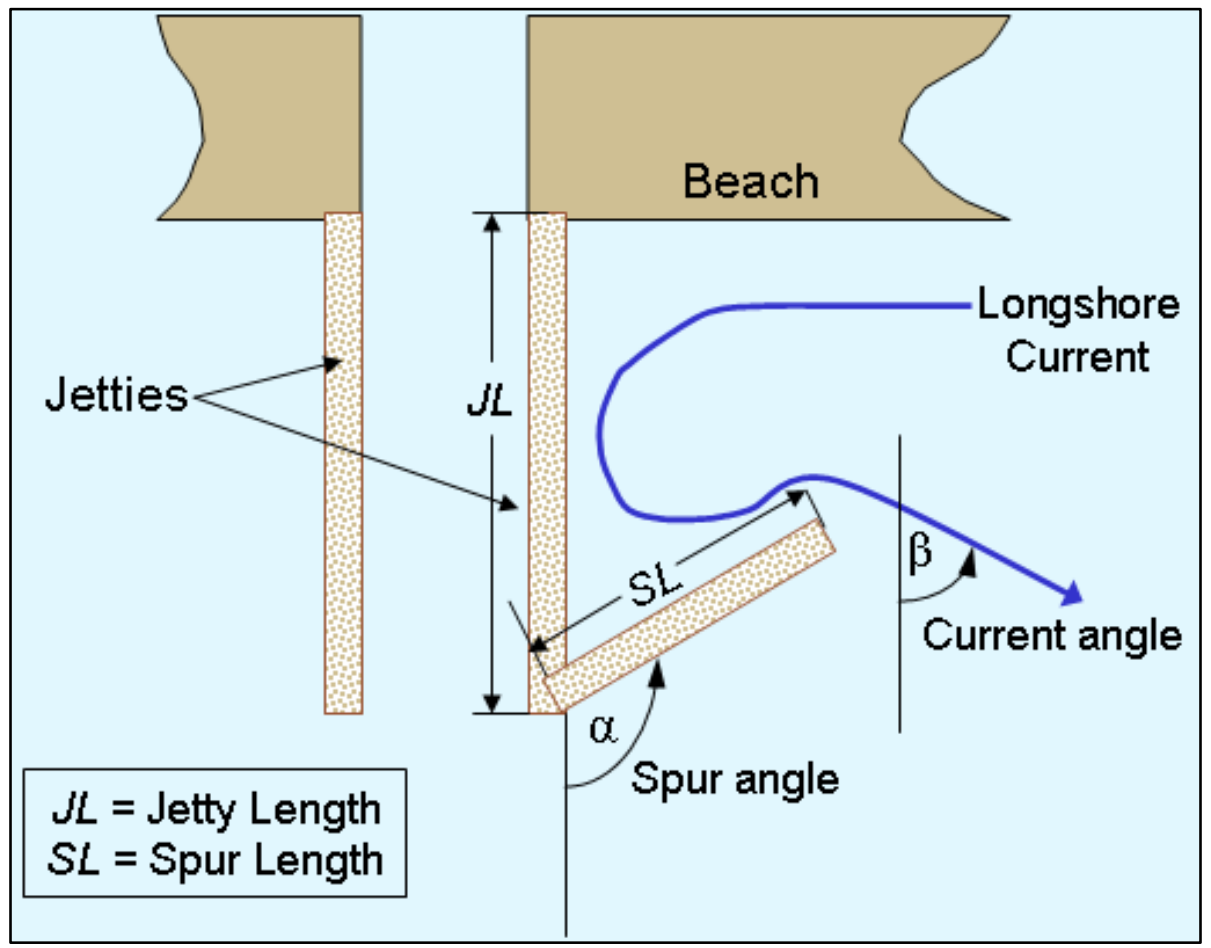

Figure 6. Definition of spur and current angles 


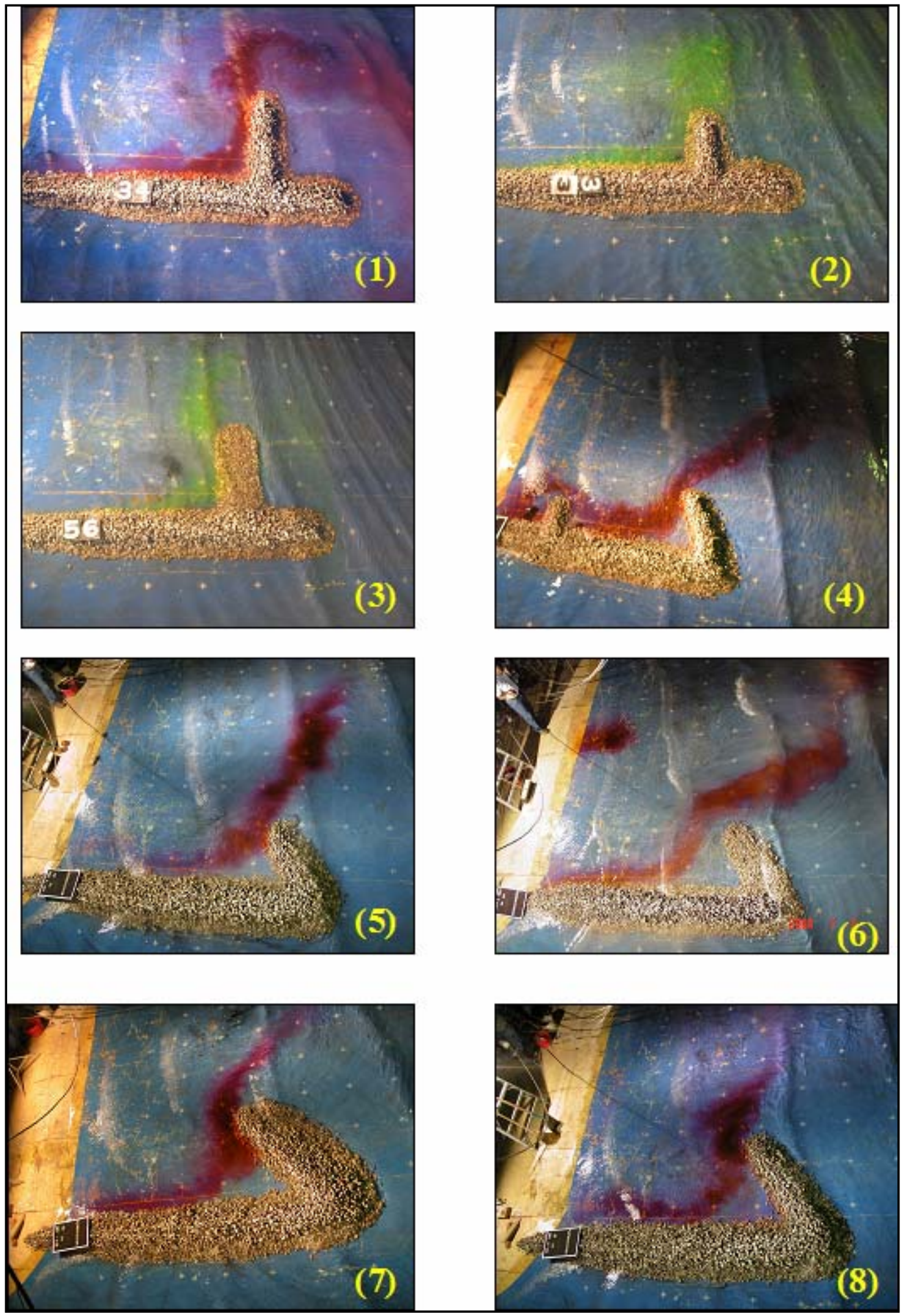

Figure 7. Eight spur jetty configurations (1-8) showing the dyed longshore current that moved alongshore toward the jetty and was diverted offshore by the jetty and spur. The current was created by a 2-m high, 11-sec period, breaking wave. Note that (3) and (6) are submerged structures 


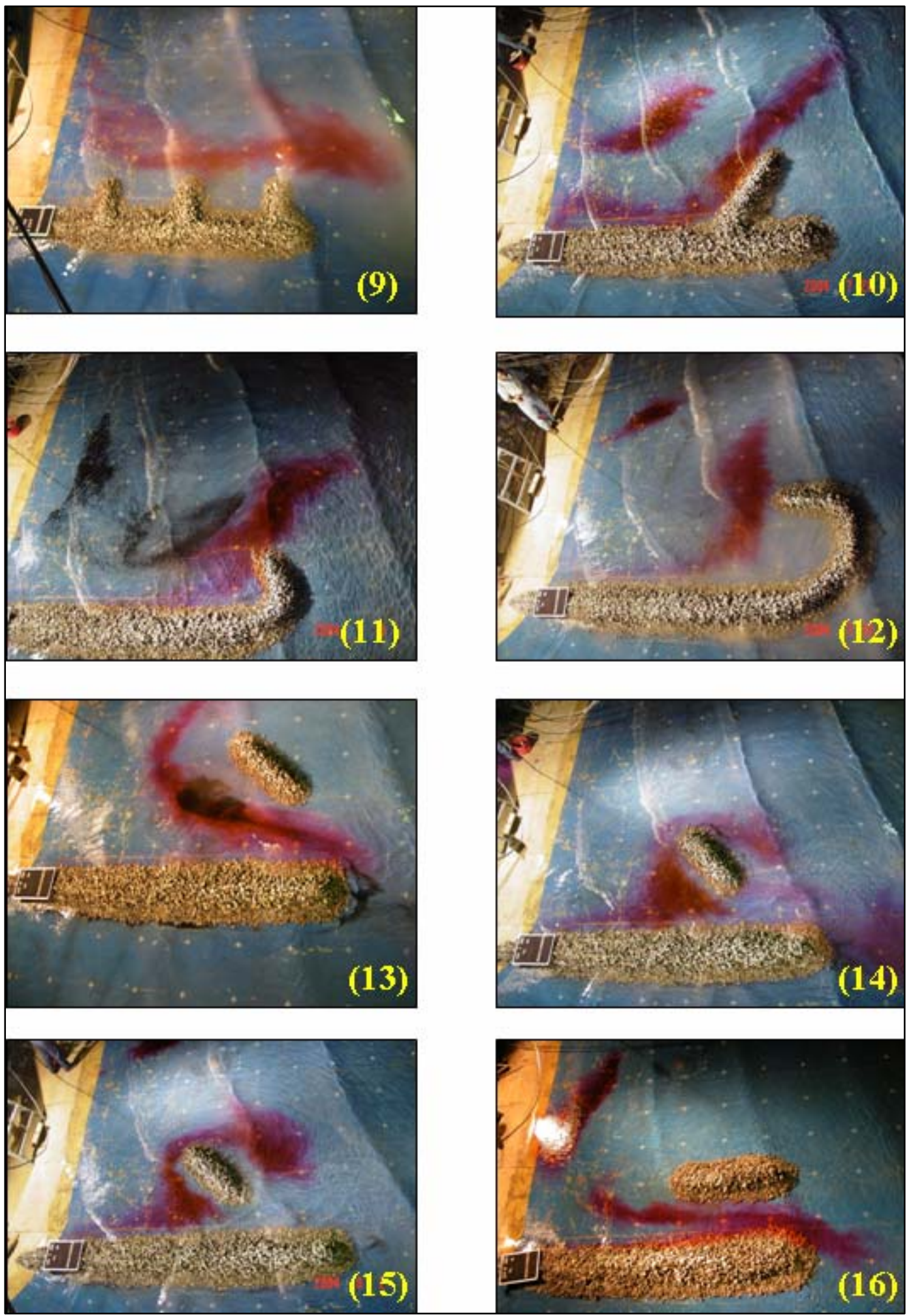

Figure 8. Eight additional spur jetty configurations (numbered 9-16) showing the dyed longshore current that moved alongshore toward the jetty and was diverted offshore by the jetty and spur. The current was created by a 2-m high, 11-sec period, breaking wave 


\begin{tabular}{|c|c|c|c|c|}
\hline \multicolumn{5}{|c|}{$\begin{array}{l}\text { Table } 1 \\
\text { Jetty Spur Description And Laboratory Results }\end{array}$} \\
\hline $\begin{array}{l}\text { Configuration } \\
\text { Number }\end{array}$ & Description & $\begin{array}{l}\text { Ratio of Spur Length, } S L \text {, } \\
\text { Relative to Jetty Length, } \\
J L\end{array}$ & $\begin{array}{l}\text { Deflection Angle of } \\
\text { Current, } B \text {, deg }\end{array}$ & $\begin{array}{l}\text { Tracer Migrating } \\
\text { Around Jetty Tip? }\end{array}$ \\
\hline 1 & \begin{tabular}{|l|} 
Connected spur, \\
perpendicular to jetty
\end{tabular} & 0.21 & 90 & YES \\
\hline 2 & \begin{tabular}{|l|} 
Connected spur, \\
perpendicular to jetty
\end{tabular} & 0.14 & 90 & YES \\
\hline 3 & $\begin{array}{l}\text { Submerged, connected spur, } \\
\text { perpendicular to jetty }\end{array}$ & 0.21 & 50 & YES \\
\hline 4 & Connected spur, $\alpha=120 \mathrm{deg}$ & 0.21 & 35 & YES \\
\hline 5 & Connected spur, $\alpha=130 \mathrm{deg}$ & 0.21 & 65 & YES \\
\hline 6 & $\begin{array}{l}\text { Submerged, connected spur, } \\
\alpha=130 \text { deg }\end{array}$ & 0.21 & 30 & YES \\
\hline 7 & Connected spur, $\alpha=130 \mathrm{deg}$ & 0.36 & 55 & NO \\
\hline 8 & Connected spur, $\alpha=130$ deg & 0.36 & 50 & NO \\
\hline 9 & $\begin{array}{l}3 \text { perpendicular spurs, evenly } \\
\text { spaced along jetty }\end{array}$ & 0.07 & 0 & YES \\
\hline 10 & Connected spur, $\alpha=50$ deg & 0.29 & 50 & YES \\
\hline 11 & Curved spur & 0.14 & 60 & NO \\
\hline 12 & Curved spur & 0.43 & 85 & NO \\
\hline 13 & $\begin{array}{l}\text { Detached spur, seaward } \\
\text { location }\end{array}$ & 0.21 & 0 & YES \\
\hline 14 & $\begin{array}{l}\text { Detached spur, shoreward } \\
\text { location and closer to jetty }\end{array}$ & 0.21 & $\begin{array}{l}\begin{array}{l}45, \text { wraps to less } \\
\text { than } 0\end{array} \\
\end{array}$ & YES \\
\hline 15 & \begin{tabular}{|l|} 
Detached spur, more \\
shoreward than (14) \\
\end{tabular} & 0.21 & 45, wraps to 0 & YES \\
\hline 16 & $\begin{array}{l}\text { Detached spur, parallel to } \\
\text { jetty }\end{array}$ & 0.29 & 0 & YES \\
\hline
\end{tabular}

SPUR JETTIES EFFECT ON CURRENTS: As can be noted in Figures 7 and 8, waves break at a distance offshore of about one-half jetty length for the illustrated cases. The modeled wave is $2 \mathrm{~m}, 11 \mathrm{sec}$. The current generated from this breaking wave is the only forcing condition. A floodtidal current was not reproduced in this set of experiments. The waves plus flood current are included in the sediment tracer experiments. These spurs are constructed seaward of the breaker zone in the range for successful design according to Sasaki and Sakuramoto (1984) guidance. However, many of the spur lengths are shorter than Sasaki and Sakuramoto's suggested guidance (spur length greater than width of the surf zone). Shorter lengths were examined to see if a small footprint structure could effectively deflect the current.

For configurations 1-12, the current was strongly deflected ("strong" meaning significantly different direction than the base, 0 -deg current) at angles greater than 30 deg from the jetty for all but one case, that shown in (9) of Figure 8 . The three short spurs of (9) were too closely spaced, so that minor circulations in the gaps between spurs did not capture the basic longshore current approaching the jetty. The two-spur configuration of (4) has enough spacing so that the longshore current is captured and then deflected. The other jetty-attached spurs deflect the current significantly. The range of current deflection varied from 30 to $90 \mathrm{deg}$, as measured 
counterclockwise from the main axis of the structure (see Figure 6). Even the submerged spurs deflected the current back upcoast due to wave breaking on the spur structure. The longer, jettyperpendicular, submerged spur deflected the current 50 deg from the jetty (configuration (3) of Figure 7), whereas the shorter, angled submerged spur (configuration (6) of Figure 7) did not deflect the current as strongly (20-deg angle from the jetty).

The angled spur configurations (4) - (8) were examined in anticipation of creating a countercurrent along the seaward face of the spur. This current could potentially be developed if the wave crest would initially make contact with the spur near its attachment to the jetty. As the wave crest moves shoreward, its contact point with the spur would travel upcoast, developing a current as it breaks along the structure. This current could then deflect the longshore current back upcoast. A possible additional benefit is that reflected wave energy, instead of increasing wave energy toward the navigation channel in terms of wave height and potential sediment movement in front of the spur, is directed upcoast, away from the entrance channel. The short-crested wave field developed by the incident and reflected wave in front of a coastal structure has been shown to create sediment paths parallel to the structure (Silvester 1975, 1977; Seabergh 1983) in the direction of shortcrested wave propagation. This transport pattern has been observed in physical models and in the field at seawalls and reefs. The angle of the spur was increased relative to the incident wave for this to occur. This angle can be defined more specifically by examining Figures 6 and 9. The spur angle, $\alpha$, should be greater than the local wave angle, $\theta$, plus $90 \mathrm{deg}$, to promote the possibility of a current along the front of the structure that is moving away from the channel. Also the shortcrested wave field created by the incident and reflected waves will propagate away from the channel, reducing likelihood of sediment movement toward the channel in the region in front of the spur.

Spur (7) of Figure 7 was widened to enhance breaking of waves, much like a rubble-mound breakwater with a bermed front (see Figure VI-2-12, Burcharth and Hughes 2003). The wider spur aided in generation of a stronger current in an upcoast (away from channel) direction than for the steeper sloped, angled spurs. Figure 10 illustrates this effect.

Spur (10) of Figure 8 is oriented similar to the Siuslaw River spurs (Pollack et al. 1995) shown in Figure 1 . The current is strongly directed offshore. The curved spurs (11, 12 of Figure 8$)$ deflect the current strongly back upcoast. The wave-generated current does not enter the curved embayment created by the spur. The detached spurs (13, 14, and 15 of Figure 8$)$ indicate that these structures must be placed close to the jetty and closer to the shore for best initial current deflection. However, the current wraps around the spur and proceeds toward the jetty for each of these detached structures.

The parallel spur (16 of Figure 8) indicates no apparent deflection of the longshore current. This configuration was designed for a multidirectional wave climate to trap sand and to be selfcleansing with regard to removal of the fillet that would accrete in the lee of the spurs (Miroshnichenko et al. 1985). Parallel structures would be placed on each side of parallel jetties. As seen in Figure 8, this configuration was not effective in deflecting the longshore current. The next section will examine the sediment response to all the spur configurations. 


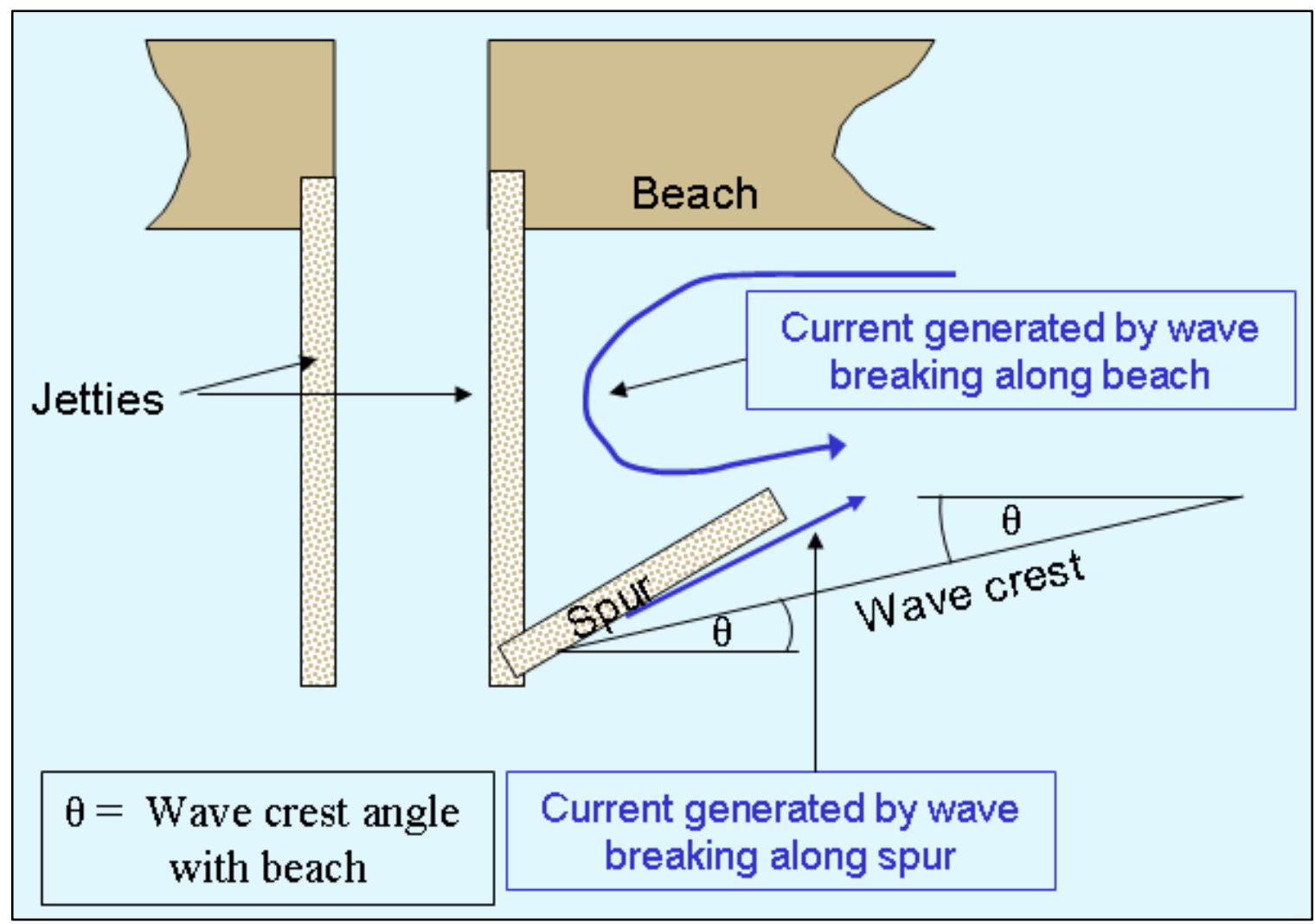

Figure 9. Benefit of angled spurs

SPUR JETTIES EFFECT ON SEDIMENT TRANSPORT: Figures 11 and 12 summarize results of sediment tracer experiments for the same spur configurations discussed previously. However, in addition to the wave-generated current, a steady-state flood flow was established to simulate a maximum flood current (scaled as $1.0 \mathrm{~m} / \mathrm{sec}$ in the navigation channel) entering the inlet. This situation would create the greatest potential for sediment to enter the navigation channel. The experiments were run for the same time duration of $30 \mathrm{~min}$ for comparability among the various configurations. A qualification for using these results for selection of the best system is the fixed-bed nature of these experiments. In the field, there would be sediment bed evolution or bathymetric change over time that might create an evolving response, e.g., create a morphology that would change the sediment pathway over time. However, the energetic nature of this region would likely reinforce similarity of sediment transport for a lengthy period of time.

As seen in Figures 11 and 12, only the angled spurs (7) and (8) and the curved spurs of (11) and (12) show no tracer movement on the channel side of the jetty. Curved spurs (11) and (12) show small amounts of tracer along the outer edge of the spur, but none had reached the channel edge. Spur (7) is the strongest indicator of a spur promoting the movement of sediment towards the beach due to the additional current upcoast on the seaward side of the spur. The spurs that reached the farthest landward and upcoast functioned the best in preventing tracer sediment from reaching the channel. 


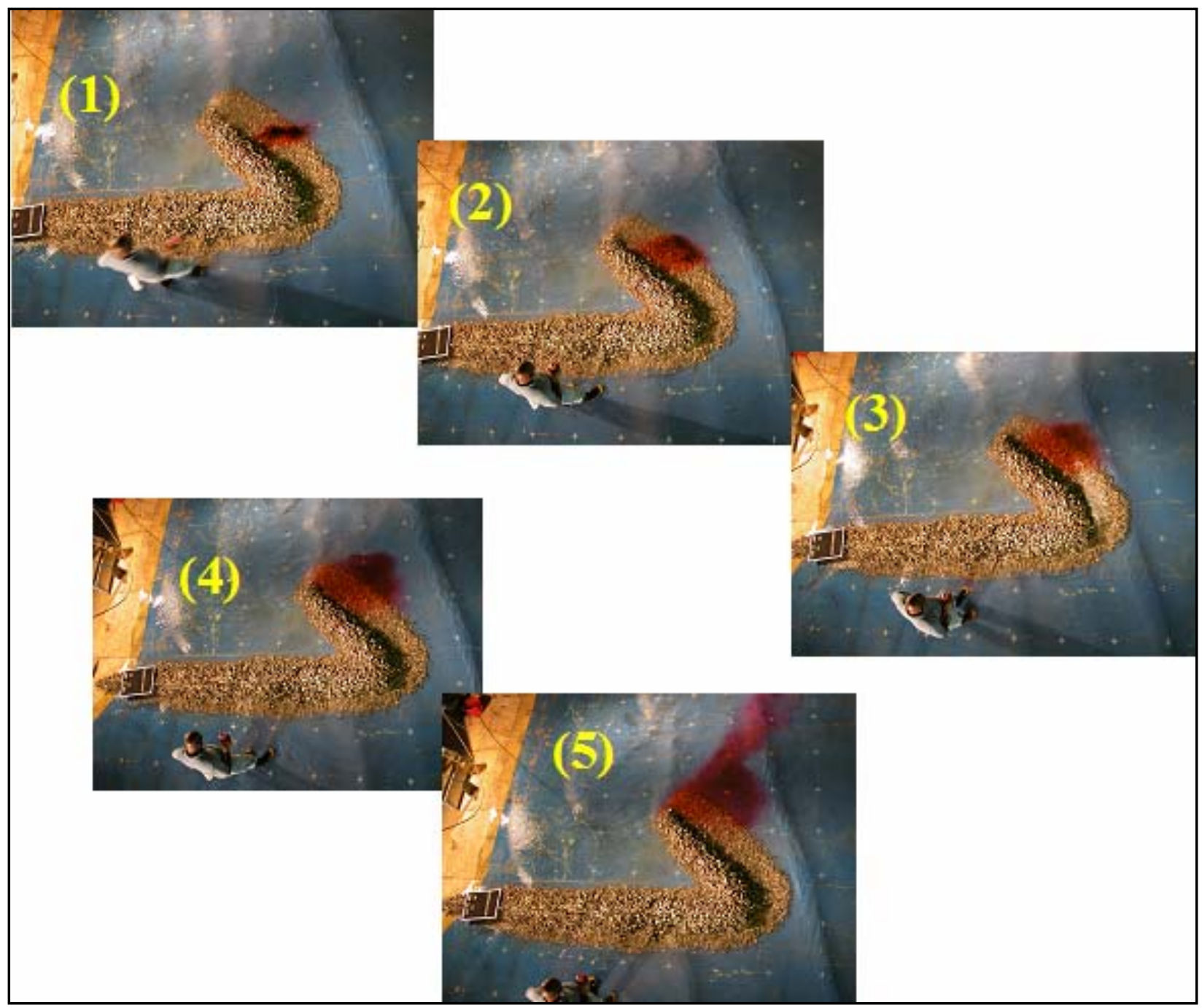

Figure 10. Angled spur showing dye movement along seaward face, upcoast, away from navigation channel (note incident wave approach)

\section{SUMMARY OF FACTORS IN SPUR JETTY DESIGN}

Spur Location. The location will depend on local conditions near the jetty, such as bottom slope, wave climate, and proximity of the shoreline. These factors will determine where waves break and where sediment transport will be greatest. The spur should be located seaward of the mean breaker position. For relatively short jetties, or a flat or gently sloping bottom, wave breaking can occur seaward of a jetty system and sediment transport will be strongest in many cases at the location of the breaker. A spur may not be as useful if this situation is frequent, as there is little opportunity to intercept and divert sediment pathways. For this situation, the jetty may need lengthening. For longer jetties, in order to maximize the likelihood of returning sand to the beach, the spur may need to be placed at some location closer to shore, or multiple spurs could be constructed. However, multiple spur design should be carefully studied to ensure diversion of the longshore current in an upcoast and shoreward direction. 


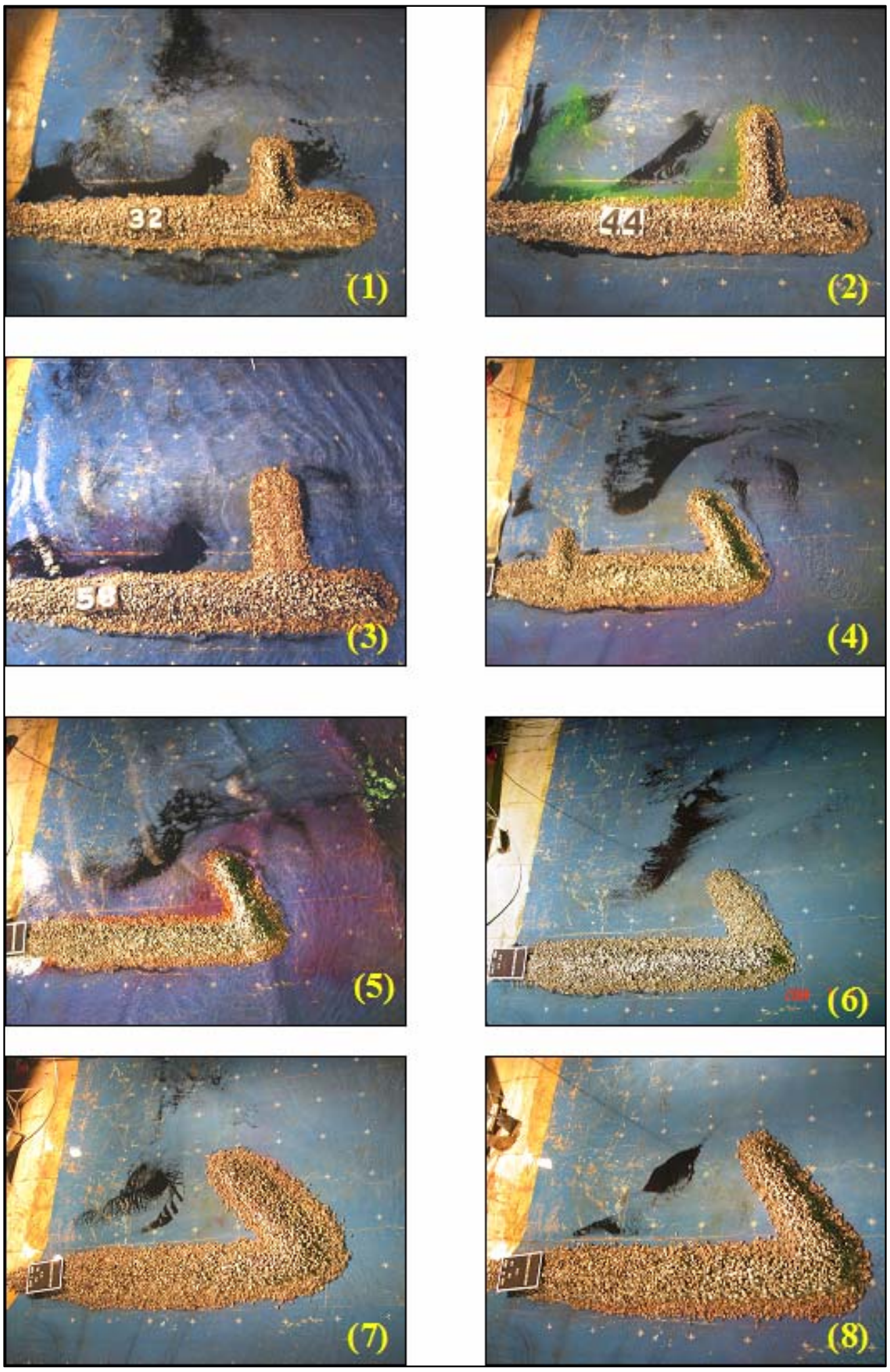

Figure 11. Eight spur jetty configurations (1-8) showing the sediment tracer moved alongshore toward the jetty and the manner diverted offshore and in some cases toward and into the navigation channel by the jetty and spur configuration. A maximum flood-tidal current and a 3.4-m high, 8-sec period wave forced the response of the tracer 


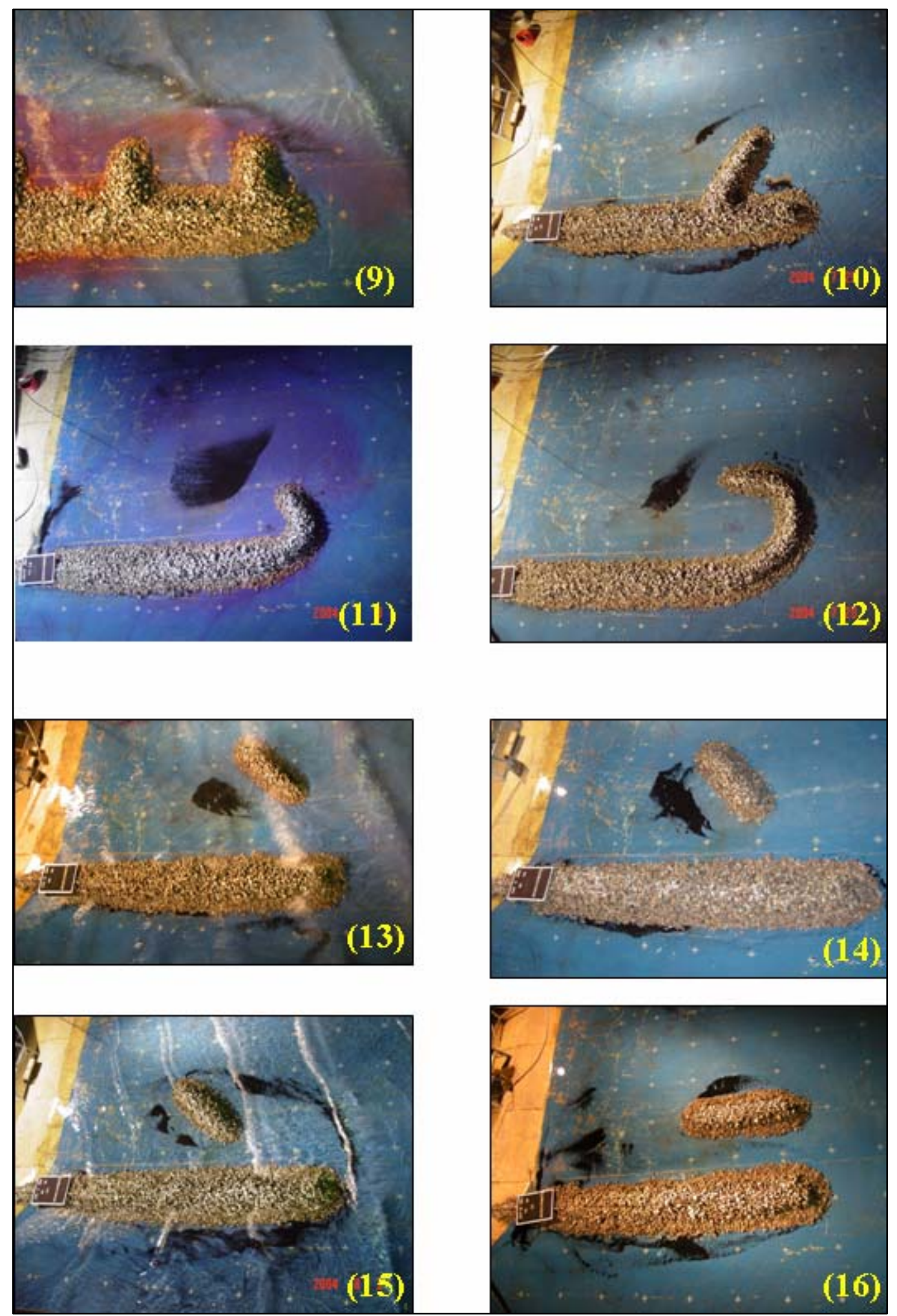

Figure 12. Eight spur jetty configurations (9-16) showing the sediment tracer moved alongshore toward the jetty and the manner diverted offshore and in some cases toward and into the navigation channel by the jetty and spur configuration. A maximum flood-tidal current and a 3.4-m high, 8-sec period wave forced the response of the tracer 
Spur Elevation. Spur elevation might typically be expected to be similar to the attached jetty. Dependent on wave climate, the spur can serve as a fishing or recreational platform if access is provided. As demonstrated previously, submerged spurs may provide similar benefits as a surfacepiercing spur, yet are less costly. However, depending on channel maintenance operations and recreational boaters, a submerged spur may create a navigation hazard, and must be appropriately marked.

Spur Length. The length of the spur should be sufficient to promote a diversion of flow from along the jetty, and retain sediment in the nearshore area rather than move it offshore towards the jetty tip. Typically one would not want the shoreline to accrete to the spur in order to preserve the potential for sand transport on the sea side of the spur minimal. If the shoreline accretes too much, the potential for sediment to work its way to the jetty tip increases. Sasaki and Sakuramoto's (1984) recommendation that length of the spurs be greater than the surf zone width appears to be reasonable. In order to maintain reasonable length, a decision based on frequency of occurrence of wave height and period (and thus surf zone width) would likely need to be made. The curved spurs (configurations 11 and 12) add length, but functioned well in preventing sediment tracer from entering the channel.

Spur Angle. These laboratory experiments indicate an advantage for having spurs at a sharp angle with the jetty (i.e., angle $>90$ deg plus local wave angle, see Figures 6 and 9). If possible, the angle chosen should be such that most local wave angles with the spur have their crest make initial contact with the part of the spur nearest the jetty. This oblique alignment creates a current along the spur that would augment the deflected longshore current. Also, reflected wave energy is diverted away from the channel, and the short-crested wave created by the incident and reflected wave would tend to produce sediment pathways in a direction away from the channel. The spur angle as defined in the text (Figure 6) should be greater than the local wave angle plus 90 deg for this enhancement to occur.

Littoral Drift Direction Concerns. Jetty spurs might be considered beneficial for a region of coast that has a balanced littoral drift environment. This is to say that typically there would be little need to bypass sediment to an eroding downcoast region if longshore transport was balanced. The spur concept is to maintain or retain sediment on one side of a jetty, reducing its likelihood to shoal an inlet navigation channel. Spurs would probably direct sediment to a location that would permit its movement back to the beach during a wave direction reversal. Rather than being impounded in the shadow of the jetty, the sediment would be more accessible to sediment reversal wave action.

If bypassing were desired, the spur could potentially direct sediment to a location for dredging. Spurs appear to be useful for beach-fill projects adjacent to coastal inlets. As the beach is adjusting to a new equilibrium shape, much sediment transport occurs. The spur would reduce the potential for this sediment to enter the navigation channel while the beach fill equilibrates.

CONCLUSIONS: There are multiple factors to consider in the design of a jetty spur. This document has provided illustrations of the effects of a variety of spur configurations on wave-and tide-generated current, and sediment tracer. 
Jetty spurs can deflect littoral sediment and the longshore current back upcoast, reducing shoaling in the navigation channel and perhaps increasing navigation reliability. These structures also have the potential to provide wave protection to the beach in the lee of the spur. In certain coastal settings, the spur-jetty system could be designed to support land-based or jet pump dredging equipment to bypass the accumulated sediments to the downcoast beach. However, the expense and benefits of such an integrated dredging system must be evaluated.

Physical and numerical models are available to develop and optimize spurs for site-specific conditions. Modeling is most likely necessary to understand complex current and sediment circulation due to varying wave parameters of height, period and direction. Also the offshore bathymetry may be a dominant factor in controlling current and sediment circulation in the region just upcoast of the jetty.

ADDITIONAL INFORMATION: Questions about this technical note can be addressed to Mr. William C. Seabergh (601-634-3788; e-mail: William.C.Seabergh@erdc.usace.army.mil. For information about the Coastal Inlets Research Program, contact the Program Manager, Dr. Nicholas C. Kraus at Nicholas.C.Kraus@erdc.usace.army.mil. Technical review by Ms. Julie Rosati and Dr. Kraus is appreciated. This technical note should be cited as:

Seabergh, W. C. (2006). "Jetty spur functional design at coastal inlets; effects on nearshore circulation and potential sediment movement," ERDC/CHL CHETNIV-66, U.S. Army Engineer Research and Development Center, Vicksburg, MS.

\section{REFERENCES}

Bottin, R. R., Jr. (1981). “Siuslaw River jetty extension, Oregon,” Letter Report, September 1981, Hydraulics Laboratory, U.S. Army Engineer Waterways Experiment Station, Vicksburg, MS.

Bottin, R. R., Jr. (1997). "Monitoring completed navigation projects, lessons learned III," Coastal Engineering Technical Note CETN VI-29, U.S. Army Engineer Waterways Experiment Station, Vicksburg, MS.

Burcharth, H. F., and Hughes, S. A. (2003). "Types and functions of coastal structures," in Coastal Engineering Manual, Part VI, Design of Coastal Project Elements, Chapter VI-2, Engineer manual 1110-2-1100, S. A. Hughes, (ed.), U.S. Army Corps of Engineers, Washington, DC.

Gravens, M. B., Kraus, N. C., and Hanson, H. (1991). "GENESIS: Generalized model for simulating shoreline change," Instruction Report CERC-89-19, U.S. Army Engineer Waterways Experiment Station, Vicksburg, MS.

Hanson, H. (1987). "GENESIS - A generalized shoreline change numerical model for engineering use," Report No. 1007, Department of Water Resources Engineering, University of Lund, Lund, Sweden.

Hanson, H. and Kraus, N. C. (1989). "GENESIS: Generalized numerical modeling system for simulating shoreline change; Report 1, Technical Reference Manual," Technical Report CERC-89-19, U.S. Army Engineer Waterways Experiment Station, Vicksburg, MS.

Kraus, N. C., and Heilman, D. J. (1997). "Packery Channel feasibility study: Inlet functional design and sand management, Report 1 of a two-part series," Technical Report TAMU-CC-CBI-96-06, Conrad Blucher Institute for Surveying and Science, Texas A\&M University-Corpus Christi, Corpus Christi, TX.

Miroshnichenko, V. G., Korolyov, V. G., Pashkin, V. P., and Shepsis, V. I. (1985). "Construction of ports and approach channels at shallow coasts," Proceedings 26th International Navigation Congress, Brussels, Section II, Maritime Ports and Seaways, Permanent International Association of Navigation Congresses, 155-167. 
Pollock, C. E., McGehee, D., Neihaus, R. W., Jr., Chesser, S. A., and Livingston, C. (1995). "Effectiveness of spur jetties at Siuslaw River, Oregon: Report 1, Prototype monitoring study," Technical Report CERC-95-14, Coastal Engineering Research Center, U.S. Army Engineer Waterways Experiment Station, Vicksburg, MS.

Sasaki, T. O., and Sakuramoto, H. (1984). "Effect of rip current barrier on harbor shoaling," Proceedings 19th Coastal Engineering Conference, American Society of Civil Engineers, ASCE Press, New York, 2,091-2,106.

Seabergh, W. C. (1983). "Weir jetty performance: Hydraulic and sedimentary considerations, hydraulic model investigation," Technical Report HL-83-5, U.S. Army Engineer Waterways Experiment Station, Vicksburg, MS.

Seabergh, W. C. (1999). "Physical model for coastal inlet entrance studies," Coastal Engineering Technical Note CETN IV-19, U.S. Army Engineer Research and Development Center, Vicksburg, MS.

Seabergh, W. C. (2002). "Weir jetties at coastal inlets, Part 1: Functional design considerations," ERDC/CHL CHETN IV-53, U.S. Army Engineer Research and Development Center, Vicksburg, MS.

Seabergh, W. C., and Krock, J. (2003). "Jetty spurs at coastal inlets for reduction of navigation channel shoaling," ERDC/CHL CHETN IV-61, U.S. Army Engineer Research and Development Center, Vicksburg, MS.

Seabergh, W. C., Lin, L., and Demirbilek, Z. (2005). "Laboratory study of hydrodynamics near absorbing and fully reflecting jetty," ERDC/CHL Technical Report TR-05-8, U.S. Army Engineer Research and Development Center, Vicksburg, MS.

Silvester, R. (1975). "Sediment transmission across entrances by natural means," Proceedings 16th International Association Hydraulic Research Congress I, 145-156.

Silvester, R. (1977). “The role of wave reflection in coastal processes," Proceedings Coastal Sediments '77, ASCE, 639-654.

Walther, M. P., and Dombrowski, M. R. (1999). "Ft. Pierce inlet spur jetty performance," Proceedings 12th Annual National Conference on Beach Preservation Technology, Florida Shore \& Beach Preservation Association, 127142 .

NOTE: The contents of this technical note are not to be used for advertising, publication,

or promotional purposes. Citation of trade names does not constitute an official endorsement or approval of the use of such products. 